Proceedings of the 2011 Winter Simulation Conference

S. Jain, R.R. Creasey, J. Himmelspach, K.P. White, and M. Fu, eds.

\title{
A COLLABORATIVE AUGMENTED REALITY BASED MODELING ENVIRONMENT FOR CONSTRUCTION ENGINEERING AND MANAGEMENT EDUCATION
}

\author{
Amir H. Behzadan \\ Asif Iqbal \\ University of Central Florida \\ 4000 Central Florida Blvd. \\ Orlando, FL 32816-2450, USA \\ University of Michigan \\ 2350 Hayward Street \\ Ann Arbor, MI 48109-2125, USA
}

\author{
Vineet R. Kamat \\ University of Michigan \\ 2350 Hayward Street \\ Ann Arbor, MI 48109-2125, USA
}

\begin{abstract}
Current instruction methods of teaching construction engineering and management rely heavily on traditional pedagogical techniques such as in-class instruction and coursework in core subjects. Such methods often fail to prepare students to effectively handle the complexities of actual projects as they provide limited opportunities for hands-on experience. For example, creating an effective relationship and intuitive mapping between the real world and the abstract knowledge gained through tools such as CAD and BIM is still a challenge. This paper presents the initial results of a project aimed to transform the current learning process in construction by designing and implementing an interactive augmented reality (AR) learning tool to help students develop a comprehensive understanding of construction equipment, processes, and operational safety. A descriptive account of how this evolving technology can be used to create a transformative learning and educational environment is provided, along with a discussion of several design and implementation challenges.
\end{abstract}

\section{INTRODUCTION}

Construction and civil engineering operations consist of human interactions with and high levels of exposure to machinery and equipment in harsh environments. Compared to other industries and despite the fact that an increasing number of construction firms have taken the lead in implementing jobsite health and safety management practices, construction still accounts for a large portion of all work related deaths (Haslam et al. 2005). According to the Census of Fatal Occupational Injuries (U.S. Bureau of Labor Statistics), construction has been the most hazardous industry in the U.S. based on the number of fatalities. With 1,178 out of 4,956 deaths of private sector workers in 2007 (almost one in four on-the-job fatalities) no other industry ranks higher than construction. As shown in Table 1, the fatality rate in construction was exceeded in only three industry groups. Also, the fatality rate in the construction industry was more than twice the average for all private sector industries (Levin 2008). Donaghy (2009) identified the "very young" as one of the two particularly vulnerable groups on every project. Workers in this group might be an apprentice, entry-level site personnel, or a casual laborer with close to no skills and experience, ignorant of their rights and obligations, and an unwillingness to challenge authority or question an instruction. 
Research indicates that problems arising from workers or the work team such as lack of training, qualifications, or instructions play a role in $70 \%$ of all construction accidents (Haslam et al. 2005).

Table 1: Top Fatality Rates of Private Sector Industries (2007)

\begin{tabular}{|l|c|}
\hline \multicolumn{1}{|c|}{ Industry } & $\begin{array}{c}\text { Fatality Rate } \\
\text { (per 100,000 employed person) }\end{array}$ \\
\hline Agriculture, forestry, fishing, and hunting & 27.3 \\
\hline Mining & 24.8 \\
\hline Transportation and Warehousing & 15.9 \\
\hline Construction & 10.3 \\
\hline Average of all private sector industries & $\mathbf{4 . 0}$ \\
\hline
\end{tabular}

Historically, the construction industry has been facing increased competition, and stringent governmental and environmental regulations while encountering issues such as labors and unions, challenges of new technologies and new materials, and construction of complex projects. These forces emphasize the importance of a steady supply of competitive and strong workforce to the industry and as a result, attracting talented students and imparting the best possible civil and construction engineering education is critical to the future of the U.S. construction industry. Despite this, the inevitable risks associated with many tasks in a typical construction project, as well as the high costs of accident recovery is an impediment to the involvement and recruitment of students and youngsters in civil and construction engineering projects. Research also shows that the brightest students entering higher education are often attracted by disciplines other than engineering that are perceived more likely to yield careers of higher prestige and greater returns. For construction engineering in particular, which has constantly maintained the slogan of "hard hat in the ditch", this is further complicated since the field is not traditionally viewed as a technology friendly discipline. Thus, student quality and enrollment in construction and civil engineering programs have been declining across North America (Nehdi 2001). While the U.S. construction industry lacks a steady supply of skilled and experienced field personnel, accumulating adequate equipment operations and safety skills through traditional methods of workforce training for those who choose to stay in this field takes significant time and has proven to be costly and inefficient. The instruction methods used to convey the engineering knowledge in the majority of construction and civil engineering curricula heavily rely on traditional means such as exposing students to applied science courses which are often inadequate in preparing them for the onsite construction tasks as they mostly lack adequate experience in the dynamics and complexity of the construction site, fall short in guidance and interaction with construction experts, and have limited access to hands-on experience. Although recent introduction of topics such as Building Information Modeling (BIM) has improved the quality of learning (Woo 2006), many students and new field personnel still fail to relate and use this abstract knowledge to real life problem solving. Even site visits that ideally form an important component of teaching/learning in many aspects may not be possible due to issues such as schedule conflicts, access difficulties, weather situations, and the overriding need for safety and liability issues. This emboldens the role of advanced computing and information technologies, simulation, and visualization to complement engineering education. In a study conducted by the Institution of Structural Engineers in the U.K., it was revealed that civil engineering education should include practicality and feel for construction engineering (Sawhney, Mund, and Koczenasz 2001). In reality, many civil and construction engineering programs fail to provide students with an arena where they can acquire the skills and experience necessary to successful professional practice and onsite performance. Most civil engineers need to spend many years in the field in order to assimilate an adequate knowledge about actual construction performance.

Given the high demand for skilled workforce in construction and civil engineering, the high level of risk associated with equipment operations on site, and the fact that appropriate operational and safety skills take long time to accumulate, the presented research aims to explore an innovative approach that integrates advanced technology into the teaching/learning experience by exploiting advanced visualization 
and sensing technologies to study, design, implement, and evaluate a potentially transformative pedagogical paradigm for engineering process education to impart the required training while providing flexibility, mobility, and ease of use. The ultimate outcome of this ongoing project will be the design and implementation of a learning tool that uses augmented reality (AR) visualization and real time object tracking to enable students to develop a comprehensive understanding of the equipment and processes and operational safety through real time interaction with a remote site.

\section{PREVIOUS WORK IN AUGMENTED REALITY}

AR is different from Virtual Reality (VR), a visualization technology that has been around for several decades. Unlike VR, AR does not completely replace the real world, rather the real world is supplemented with relevant synthetic information, and thus real and virtual objects coexist in an augmented space (Azuma 1997). AR is a powerful visualization technique with potential applications in diverse scientific and engineering fields. For example, visualization of medical information projected onto a patient's body is one of the established applications of AR technology (Barfield and Caudell 2001). AR has also been used in military applications. For instance, the Battlefield Augmented Reality System (BARS) is an AR system that can network multiple dismounted war fighters together with a command center and supports information gathering and human navigation for situation awareness in urban settings (Livingston et al. 2002). Previous studies have also explored AR for a number of architecture and construction applications. For example, Roberts et al. (2002) used AR to overlay locations of subsurface utility lines onto real world views in order to demonstrate the potential of AR in helping maintenance workers avoid buried infrastructure and structural elements. Kamat and El-Tawil (2005) used AR to study the extent of horizontal displacements sustained by structural elements due to extreme loading conditions. Wang and Dunston (2006) studied the potential of AR as an assistant viewer for computer-aided drawing.

More recently, Behzadan and Kamat (2009) designed and implemented ARVISCOPE, a general purpose 3D visualization environment capable of animating simulation models of dynamic engineering operations in outdoor AR. ARVISCOPE supports real time communications with Global Positioning System (GPS) and motion tracking devices in order to create and constantly update live AR animations of an engineering operation displayed to a mobile observer. Another major outcome of this research was ROVER, a mobile computing apparatus designed to address the problem of georeferenced registration which historically has been a major research challenge in outdoor AR (Behzadan, Timm, and Kamat 2008). A proper registration results in objects in the real world and superimposed virtual objects precisely aligned in the global coordinate system (i.e., longitude, latitude, and altitude) with respect to each other. When used together, ARVISCOPE and ROVER can create interactive AR animations of any length and complexity. The designed framework is compatible with commonly accepted data transfer protocols (Behzadan and Kamat 2007).

\section{AUGMENTED REALITY AND LEARNING PROCESS}

The application of AR as a learning tool supports the paradigm of "constructivism" in which learning takes place when students can build conceptual models that are both consistent with what they already understand and with the new content. Such models can be further enhanced by integrating types of information other than just simple 3D representations. These types can include audio, text annotations, 2D images, and diagrams. AR can enhance the traditional learning experience since:

- The ability to learn concepts and ideas through interacting with a scene (constructivism learning theory) facilitates the generation of knowledge and skills that otherwise would take too long to accumulate.

- Making mistakes during the learning process will have literally no real consequence for the educator whereas in traditional learning, failure to follow certain rules or precautions while operating 


\section{Behzadan, Iqbal, and Kamat}

machinery or handling a certain hazardous material would lead to serious safety and health related problems.

- AR supports discovery-based learning which refers to a learning technique in which students take control of their own learning process, acquire information, and use that information in order to experience scenarios which may not be feasible to construct in reality given the time and space constraints of a typical engineering project.

- By providing multiple students access to a shared augmented space populated with real and virtual objects, they are encouraged to become involved in teamwork and brainstorming activities in order to solve a problem which at the same time, helps them improve their communication skills.

A limited amount of previous work has explored the educational applications of visualization techniques. For example, Klopfer, Squire, and Jenkins (2002) studied the potential of AR in environmental engineering education where students used location-aware handheld computers (equipped with GPS) to physically move throughout a real world location while collecting place-dependent simulated field data and collaboratively investigating simulated scenarios. Kaufmann and Schmalstieg (2003) developed Construct3D, a mobile collaborative AR application designed for mathematics and geometry education. Liarokapis et al. (2004) presented an educational application that allowed users to interact with 3D Web content in VR and AR. Four mechanical engineering themes (machines, vehicles, platonic solids and tools) were also illustrated to demonstrate the use of the system to support learning. Hughes et al. (2005) described their efforts to transform core mixed reality technology and methods into the diverse applications of urban terrain, used for military training and situational awareness, and community learning. Chen (2006) investigated how students interact with AR and physical models and evaluated their perceptions in learning about amino acids. The results showed that some students liked to manipulate AR by rotating the markers to see different orientations of the virtual objects and some preferred to interact with physical models in order to get a feeling of physical contact. The project concluded that students tended to treat AR as real objects.

\section{METHDOLOGY}

By presenting contextual information in textual or graphical format, the user's view of the real world is enhanced or augmented beyond the normal experience. The addition of such contextual computergenerated information spatially located relative to the user can assist in the performance of several scientific and engineering tasks. For this reason, AR enabling technologies have been researched in an increasing number of studies in recent years. AR is different from Virtual Reality (VR), a visualization technology that has been around for several decades. Unlike VR, AR does not completely replace the real world, rather the real world is supplemented with relevant synthetic information, and thus real and virtual objects coexist in an augmented space. The real advantage of AR is that the view of the real world is used as a readymade backdrop for displaying superimposed information (e.g., graphics, sound, diagrams) of interest. An AR user only needs to create and overlay information that needs to be augmented onto the real world view and as a result, recreating the whole surrounding environment will not be a concern in AR. At the same time, by bringing the real world into the visualization, the user (as a real object in that world) will become part of the AR experience and hence, can interact with both real and virtual objects on a fullscale real time basis.

There are two major categories of AR visualization technologies: marker-less, and marker-based. A marker is a 2D graphical symbol printed on a sheet of paper to which a piece of information (e.g., video, audio, text, diagram, or graphics) is assigned. In marker-less AR, markers are not used and the condition under which a virtual object is displayed is defined by the user. For example, the user can specify that a virtual object is always displayed at a certain 2D coordinate on an AR display. In marker-based AR, a virtual object is displayed only if its corresponding marker pattern is visible. A well-known example of marker-based AR is the Lego Digital Box technology used in Downtown Disney (Orlando, FL). As 


\section{Behzadan, Iqbal, and Kamat}

shown in Figure 1, kids hold a Lego box in front of a camera and the animated 3D model of the completed Lego set is superimposed and displayed on top of the box when the box is visible to the camera.

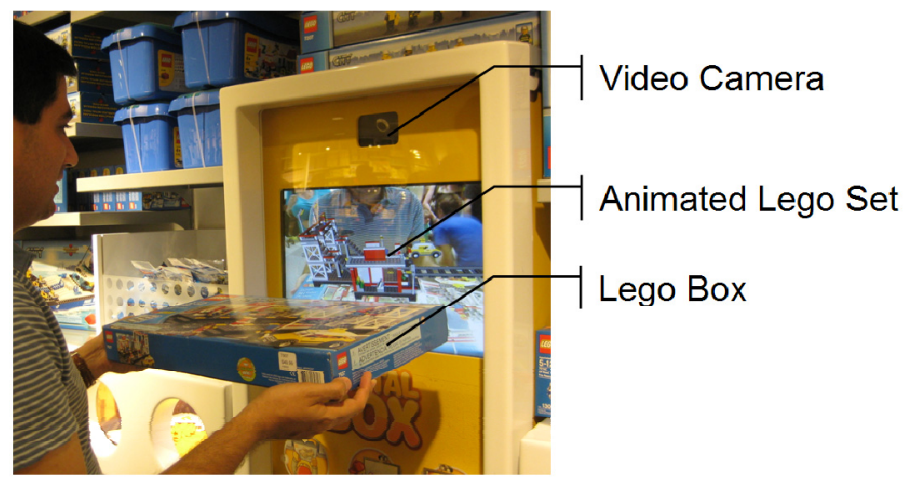

Figure 1: Kids can see a completed Lego set using the Lego Digital box Technology in Downtown Disney

In a more recent effort, PBS and the Corporation for Public Broadcasting are using part of a \$72 million grant from the U.S. Department of Education to test whether AR games can help young children with skills like sorting and measuring. PBS rolled out a prototype game in 2010 with its "Dinosaur Train" series. Children can print out a picture of a dinosaur egg and manipulate it in front of a camera to make the egg hatch onscreen. PBS is also testing AR games that use mobile devices, including one targeted at preschoolers about a dinosaur dig where children find, sort and measure virtual bones. Another "Dinosaur Train" game that merges technology and reality lets children and their parents use GPS-enabled devices to find "geocaches" (boxes that are hidden at specific coordinates and contain dinosaur-themed material). In this research, marker-based AR will be used. In particular, sheets of paper containing markers are bound together to form an "AR Book". The proposed AR learning system does not completely replace the existing instruction methods; rather it is intended to support and strengthen the conventional face-to-face instruction while enabling instructors and students to blend the real world and a virtual collaborative environment. Figure 2 is an overall representation of the proposed AR learning tool.

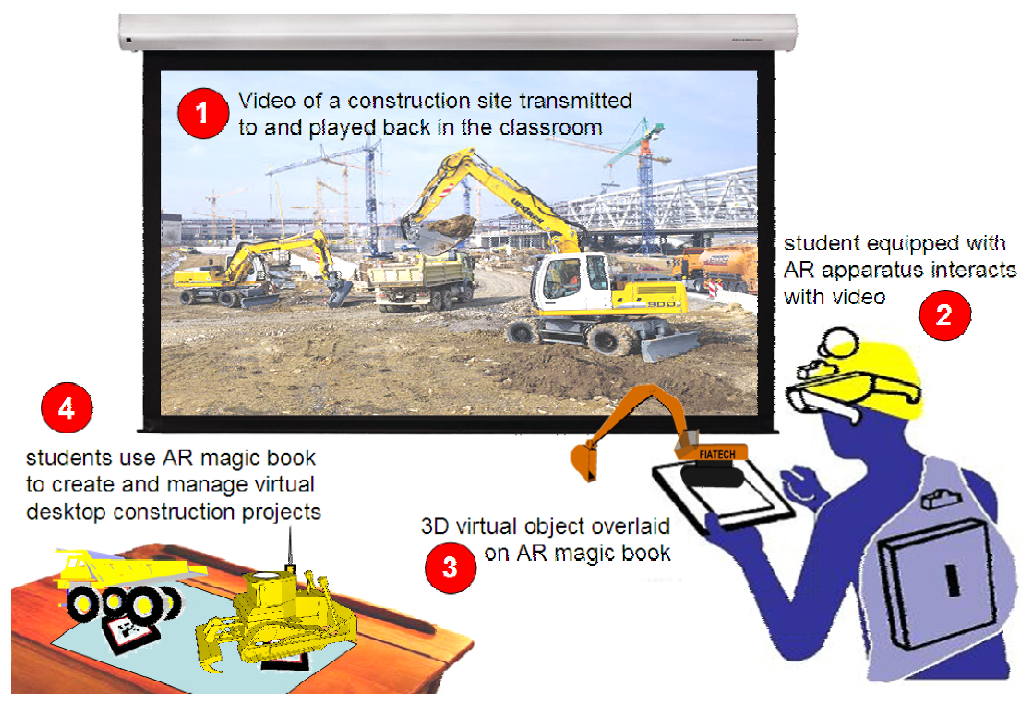

Figure 2: Major steps in bringing the collaborative augmented reality learning experience to the classroom

As shown in this Figure, each student is equipped with an AR head-mounted display (HMD) which enables viewing of augmented information and graphics overlaid on the markers inside the Magic Book. 
When a marker is visible through the HMD the corresponding information is shown to the student. The learning experience starts with real time video streams of a remote construction jobsite captured by an IPaddressable camera, transmitted via the internet to the classroom, and played back on a large projection screen (Step 1). The global position of the camera (i.e., longitude, latitude, and altitude) is also obtained by mounting a GPS device on top of the camera. In order to identify an object in the video (e.g., crane, excavator, hauler), it is essential to geo-reference that object by capturing its global position. To achieve this, site personnel mount a GPS device on each object of interest prior to the experience. The positional information is constantly sent to the system. Knowing the latest global position of the camera (viewpoint) and each object of interest, the 3D global position of an object will then be transformed to the local 2D coordinate of the projection screen with the camera located at the center point of the screen. Students will then be able to walk up to the screen while carrying their Magic Books and watch the video stream. Each student will have the ability to interact with the scene and retrieve information about an object by wearing a smart glove equipped with a touch sensor (e.g., an RFID tag) (Step 2). As the student moves his or her finger on the screen, the local position of the student's finger is captured by a network of data receivers (e.g., RFID readers) installed in predetermined positions. At least three data receivers will be needed in order to precisely calculate the finger position through triangulation in the local 2D coordinate of the projection screen. An additional (fourth) data receiver is also used to increase accuracy and eliminate any potential errors in locating the position of the RFID tag on the projection screen. As shown in Figure 3, these data receivers are mounted on the corners of the screen to provide an uninterrupted clear line of sight. When the student's finger moves close to an object in the video (when the distance between the finger's position and an object's position is less than a certain threshold), relevant information (e.g., 2D or 3D models, manufacturer's data, loading charts, work schedule) are displayed to the student through the HMD on Magic Book markers (Step 3). Students can also move their Magic Books around the room to form groups, virtually manage a project, discuss a certain scenario, and explore alternative solutions in a collaborative setting, while learning basic concepts such as equipment operations, jobsite safety, resource utilization, work sequencing, and site layout (Step 4).

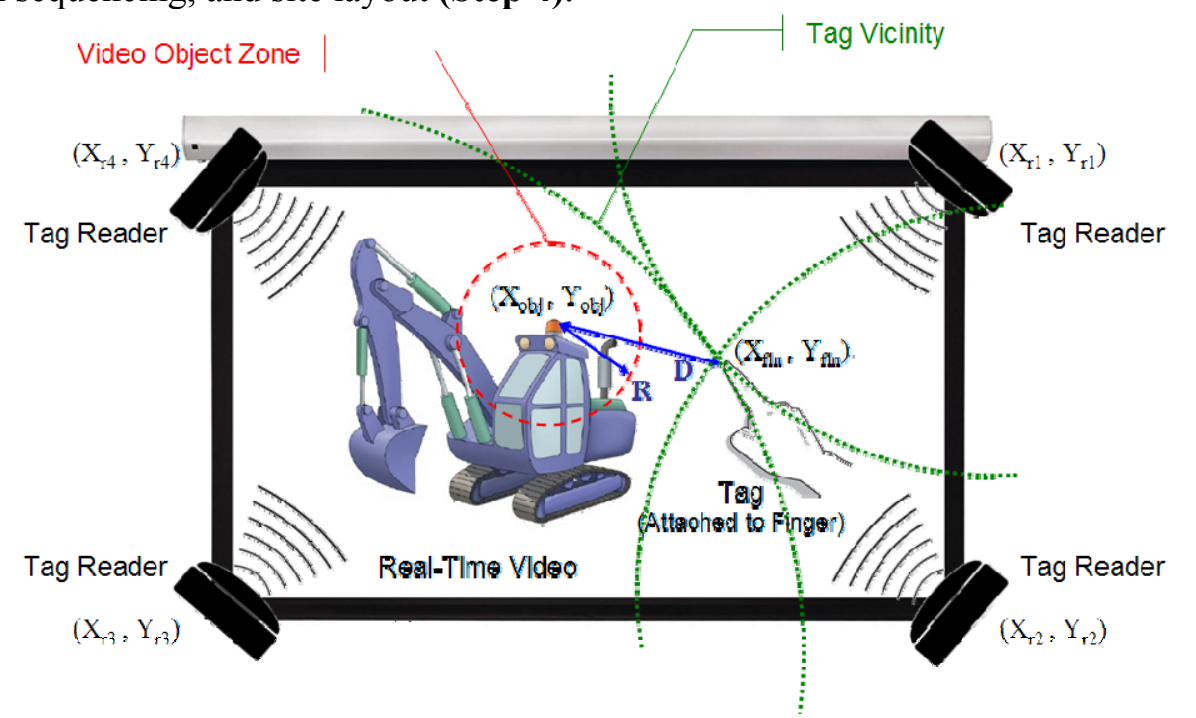

Figure 3: As soon as the distance between the tag and the calculated object zone is less than a minimum threshold, relevant information is augmented and displayed on the MagicBook markers

\section{PROOF-OF-CONCEPT EXPERIMENTS}

The authors have successfully developed GEN-1, the first generation MagicBook. GEN-1 is a simple implementation of an AR-enhanced book that was completely implemented in Visual Studio .NET, using AR Toolkit. GEN-1 helps students gain a better understanding of construction equipment through observing and manipulating overlaid 3D virtual models while reading corresponding technical information. Fig- 


\section{Behzadan, Iqbal, and Kamat}

ure 4 shows sample pages of GEN-1 as well as snapshots of two validation experiments conducted by the authors. The authors are currently working on designing larger scale tests that can be conducted in a classroom setting where students carry their own MagicBooks and learn the basics of construction equipment in a collaborative environment.
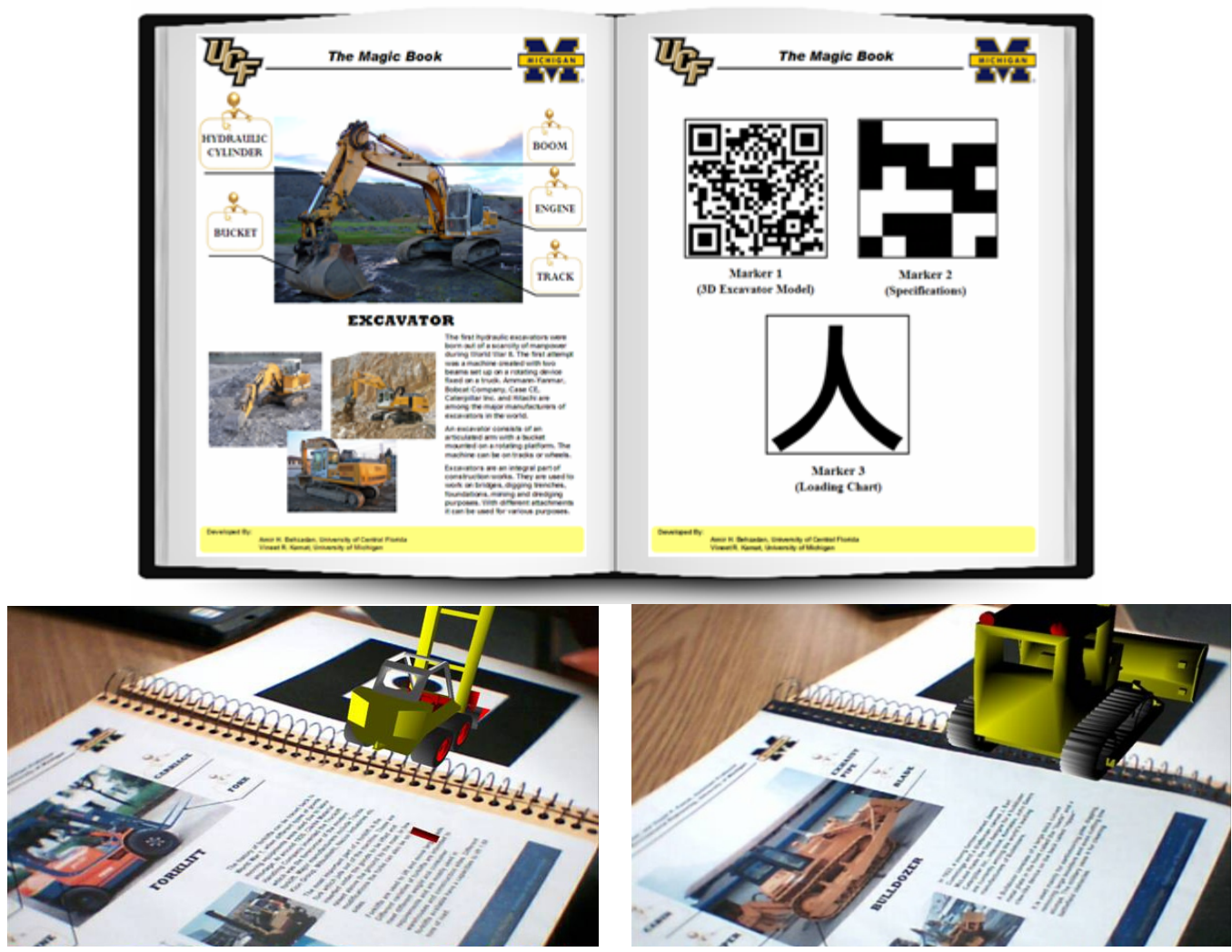

Figure 4: GEN-1 MagicBook was successfully designed and used to conduct proof-of-concept experiments by the authors

\section{CONCLUSIONS AND FUTURE WORK}

Recent advances in the development of pedagogical concepts, applications and technology, and a simultaneous decline in hardware costs, has resulted in a wide-spread use of small-scale and mobile systems in education. When properly implemented, computer technology has a significant effect on student achievement, stimulated increased instructor-student interaction, encouraged cooperative learning, collaboration, problem-solving, and student inquiry skills. What is essential is to make technology a ubiquitous resource in the learning process, personalize it based on students' individual needs and learning styles, and then ask instructors to mentor and facilitate the use of technology while students learn, direct, and collaborate in a technology-rich environment. Integrating technology into the curriculum in today's schools should not mean finding ways that computers can help instructors teach the same old topics in the same old ways. Instead, instructors must have the opportunity to combine technology with emerging models of teaching and learning to transform education.

In this paper, the latest results of an ongoing research aimed at the possibility of a new collaborative AR-based learning technology were presented. In addition to the technical aspects of this project, the educational efficacy and value of the developed system will be evaluated by conducting extensive studentcentered assessments. The results will provide a basis to constantly improve the techniques. Such evaluations will not be limited to usability issues of the AR learning tool rather a major emphasis will be put on 


\section{Behzadan, Iqbal, and Kamat}

its capability to support students' learning. The key hypothesis of the evaluation process is that through seeing engineering objects in 3D augmented space and interacting with them, students' understanding of the equipment and processes and operational safety will be enhanced.

\section{REFERENCES}

Azuma, R. 1997. “A Survey of Augmented Reality.” Teleoperators and Virtual Environments 6(4):355385. MIT Press.

Barfield, W., and T. Caudell. 2001. Fundamentals of Wearable Computers and Augmented Reality. Mahwah, New Jersey: Lawrence Erlbaum Associates.

Behzadan, A. H., and V. R. Kamat. 2007. "Reusable Modular Software Interfaces for Outdoor Augmented Reality Applications in Engineering." In Proceedings of the International Workshop on Computing in Civil Engineering, 825-837. Reston, Virginia: American Society of Civil Engineers.

Behzadan, A. H., and V. R. Kamat. 2009. "Automated Generation of Operations Level Construction Animations in Outdoor Augmented Reality." Computing in Civil Engineering23(6):405-417. ASCE.

Behzadan, A. H., B. W. Timm, and V. R. Kamat. 2008. "General-Purpose Modular Hardware and Software Framework for Mobile Outdoor Augmented Reality Applications in Engineering." Advanced Engineering Informatics 22(1):90-105. Elsevier Science.

Chen, Y. C. 2006. "A Study of Comparing the Use of Augmented Reality and Physical Models in Chemistry Education." In Proceedings of the ACM International Conference on Virtual Reality Continuum and Its Applications (VRCIA), 365-372. New York, New York: Association for Computing Machinery.

Donaghy, R. 2009. "One Death Is Too Many: Inquiry into the Underlying Causes of Construction Fatal Accidents." Report to the Secretary of State for Work and Pensions, TSO, Norwich, United Kingdom.

Haslam, R. A., S. A. Hide, A. G. F. Gibb, D. E. Gyi, T. Pavitt, S. Atkinson, and A. R. Duff. 2005. "Contributing Factors in Construction Accidents." Applied Ergonomics 36:401-415. Elsevier Science.

Hughes, C. E., C. B. Stapleton, D. E. Hughes, and E. M. Smith. 2005. "Mixed Reality in Education, Entertainment, and Training." Computer Graphics 25(6):24-30. IEEE.

Kamat, V. R., and S. El-Tawil. 2005. "Evaluation of Augmented Reality for Rapid Assessment of Earthquake-Induced Building Damage." Computing in Civil Engineering 21(5):303-310. ASCE.

Kaufmann, H., and D. Schmalstieg. 2003. "Mathematics and Geometry Education with Collaborative Augmented Reality." Computers and Graphics 27(3):339-345. Elsevier Science.

Klopfer, E., K. Squire, and H. Jenkins. 2002. "Environmental Detectives: PDAs as a Window into a Virtual Simulated World." In Proceedings of the International Workshop on Wireless and Mobile Technologies in Education, 95-98. Piscataway, New Jersey: Institute of Electrical and Electronics Engineers.

Levin, L. 2008. "Worker Safety in the Construction Industry: The Crane and Derrick Standard." Report for Congress RL-34658, Congressional Research Service (CRS), Washington, District of Columbia.

Liarokapis, F., N. Mourkoussis, N. White, J. Darcy, M. Sifniotis, P. Petridis, A. Basu, and P. F. Lister. 2004. "Web3D and Augmented Reality to Support Engineering Education." World Transactions on Engineering and Technology Education 3(1):11-14. WIETE.

Livingston, M. A., L. J. Rosenblum, S. J. Julier, D. Brown, Y. Baillot, J. E. Swan II, J. L. Gabbard, and D. Hix. 2002. "An Augmented Reality System for Military Operations in Urban Terrain." In Proceedings of the Interservice/Industry Training, Simulation, and Education Conference, 89. Arlington, Virginia: National Training and Simulation Association.

Nehdi, N. 2001. "Crisis of Civil Engineering Education in Information Technology Age: Analysis and Prospects." Journal of Professional Issues in Engineering Education and Practice - ASCE 128(3):131-137. 
Roberts, G. W., A. Evans, A. Dodson, B. Denby, S. Cooper, and R. Hollands. 2002. "The Use of Augmented Reality, GPS, and INS for Subsurface Data Visualization." In Proceedings of FIG XXII International Congress, Washington, D.C.

Sawhney, A., A. Mund, and J. Koczenasz. 2001. "Internet-Based Interactive Construction Management Learning System." Construction Education, Associated Schools of Construction (ASC), 6(3):124138.

Wang, X., and P. S. Dunston. 2006. "Potential of Augmented Reality as An Assistant Viewer for Computer-Aided Drawing." Computing in Civil Engineering 20(6):437-441. ASCE.

Woo, J. H. 2006. "BIM (Building Information Modeling) and Pedagogical Challenges." In Proceedings of the $43^{\text {rd }}$ ASC National Annual Conference. Washington, District of Columbia: American Chemistry Society.

\section{AUTHOR BIOGRAPHIES}

AMIR H. BEHZADAN is an Assistant Professor of Construction Engineering at the University of Central Florida (UCF). He received a Ph.D. in Civil Engineering from the University of Michigan in 2008. He received his Master's degree in Construction Engineering and Management from the same university in 2005. He also holds a BE degree in Civil Engineering from Sharif University of Technology (Iran). His current research interests include automation, interactive visualization, and decision support for construction systems. He is a member of ASCE and ASEE. His e-mail address is amir.behzadan@ucf.edu and his web address is http://pegasus.cc.ucf.edu/ abehzada.

ASIF IQBAL is a Visiting Student Researcher in the Department of Civil and Environmental Engineering at the University of Michigan. He received a Bachelor of Technology degree in Civil Engineering from the Indian Institute of Technology (IIT) in Mumbai, India in 2009. His research interests are in virtual and augmented reality visualization and their application in visual simulation. His e-mail address is iasif@umich.edu.

VINEET R. KAMAT is an Associate Professor in the Department of Civil and Environmental Engineering at the University of Michigan. He received a Ph.D. in Civil Engineering at Virginia Tech in 2003; a M.S. in Civil Engineering at Virginia Tech in 2000; and a B.E. degree in Civil Engineering from Goa University (Goa, India) in 1998. His primary research interests include virtual and augmented reality, simulation, information technology, and their applications in Civil Engineering. His email and web addresses arevkamat@umich.edu and http://pathfinder.engin.umich.edu. 